\title{
Catalysis by pure graphene - From supporting actor to protagonist through shape complementarity
}

\author{
Asja A. Kroeger and Amir Karton* \\ School of Molecular Sciences, The University of Western Australia, 35 Stirling Highway, Crawley WA 6009, Australia
}

\begin{abstract}
In most catalytic applications graphene is either functionalized or acts as the catalyst support. DFT calculations show on the example of the racemizations of binaphthyl compounds that pure unmodified graphene can directly catalyze chemical processes through stabilizing non-covalent $\pi-\pi$ interactions resulting from shape complementarity between transition structures and catalyst.
\end{abstract}

Graphene, a purely carbon-based two-dimensional material consisting of a honeycomb lattice of six-membered rings, has been extensively studied for its numerous exceptional properties such as its conductivity and mechanical strength. ${ }^{1}$ While its ability to non-covalently bind and stabilize ground state molecules through non-covalent $\pi-\pi$ interactions has been well studied and led to applications in sensors and extraction devic$\mathrm{es}^{2-5}$ this principle remains surprisingly unexplored for the stabilization of transition structures. Given the current interest in metal-free catalysis, ${ }^{6-7}$ expanding the application of this concept to transition structures has the potential to open up new opportunities for applications of graphene in catalysis.

Although graphene itself is not an entirely new material in the field of catalysis, its role has largely been limited to that of a catalyst support. When directly involved in catalysis, the graphene lattice is generally modified and activation barrier reductions are achieved through interactions of reactants with substituents, defects, or dopants. ${ }^{8-11}$ The application of pure unmodified graphene as a catalyst is in its infancy. Examples are currently limited to two theoretical studies examining its effect on the barriers towards inversions in polycyclic aromatic hydrocarbon fragments, most notably the bowl-to-bowl inversions of corannulene and sumanene. ${ }^{12-13}$

$\pi-\pi$ Interactions have recently gained recognition as an important part of the catalyst design toolbox for enhancing reaction selectivity. ${ }^{14-19}$ Nevertheless, they generally play a supporting role in catalysis, typically providing small additional stabilizations alongside stronger non-covalent interactions.

Applying the simple concept of disproportionate shape complementarity between transition structure and catalyst compared to reactant and catalyst, we herein explore the possibility to lower the activation energy of a chemical process through stabilizing non-covalent $\pi-\pi$ interactions between transition structure and graphene nanoflake. To this end we turn to the simple exemplary chemical transformation of the racemization of binaphthyl derivatives catalyzed by a circumcircumcoronene graphene flake $\left(\mathrm{C}_{96} \mathrm{H}_{24}\right)$. We find a significant catalytic effect originating from $\pi-\pi$ interactions and shape complemen- tarity between transition structure and catalyst indicating a potential for applications of unmodified graphene in catalysis beyond its typical use as a catalyst support.

Being one of the most common motifs in the backbones of asymmetric metal and organocatalysts, ${ }^{20-22}$ the racemizations of biaryl compounds have been studied extensively both computationally and experimentally. ${ }^{23-39}$ Here, we focus on the racemizations of 1,1'-binaphthyl (1) and its synthetically highly relevant derivative 1,1'-binaphthyl-2,2'-diol (BINOL) (2) which forms the starting material to a myriad of chiral catalysts. ${ }^{20-22}$ Table 1 gives experimentally determined rotational barriers for compounds $\mathbf{1}$ and $\mathbf{2}$.

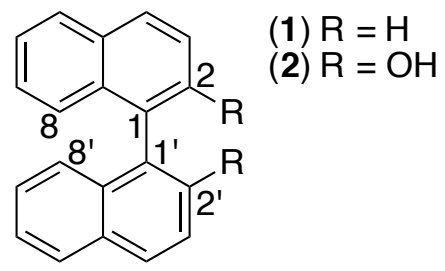

Table 1 Experimental racemization Gibbs-free reaction barrier heights for compounds 1 and $2\left(\mathrm{~kJ} \mathrm{~mol}^{-1}\right)$.

\begin{tabular}{|c|c|c|c|c|}
\hline Comp. & Solvent & $\mathbf{T}\left({ }^{\circ} \mathrm{C}\right)$ & $\Delta G^{\ddagger}$ & Ref. \\
\hline 1 & benzene & 44 & 100.7 & 24 \\
\hline 1 & DMF & 50 & 98.5 & 25 \\
\hline 2 & diphenyl & 220 & 158.0, & 31,32 \\
& ether & & 165.4 & \\
\hline
\end{tabular}

The transition state geometries of binaphthyl inversions have been the focus of a number of computational mechanistic studies and a total of four general pathways have been proposed. $^{23,25-26,28-33,36,39}$ These include two anti-type pathways with passage of the substituents in the 2 and 8 positions, and two syn-type routes corresponding to the passage of the 2 and 2 ' and 8 and 8' substituents. For both the syn and anti pathways, transition structures of two different symmetries, namely anti- $\mathrm{C}_{\mathrm{i}}$, anti- $\mathrm{C}_{2}$, syn- $\mathrm{C}_{2}$ and syn- $\mathrm{C}_{\mathrm{s}}$ are conceivable. The first study investigating the racemization of binaphthyl compounds 
al. $^{31}$ using density functional theory (DFT) methods by Meca et

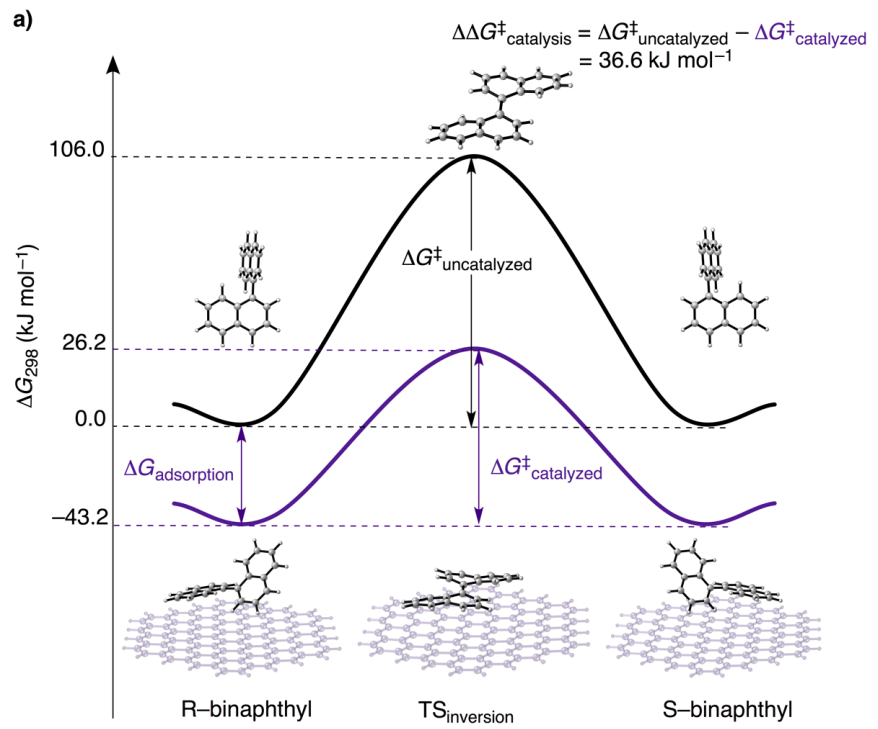

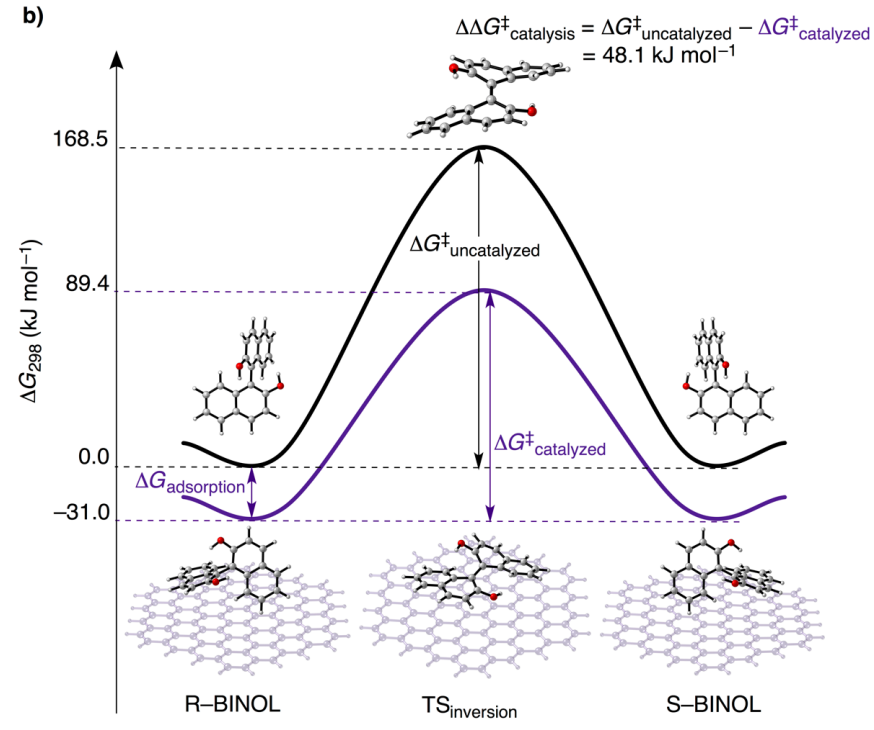

b)

Figure 3. Schematic potential energy profiles for the racemization of $\mathbf{1}$ (a) and $\mathbf{2}$ (b) illustrating the catalytic effect of the graphene flake. found that of those four possible transition structures two, the anti- $\mathrm{C}_{\mathrm{i}}$ and the syn- $\mathrm{C}_{2}$-type transition structures, could be located in the case of the 1,1'-binaphthyl inversion. For BINOL three transition structures, namely those of anti- $\mathrm{C}_{\mathrm{i}}$, syn- $\mathrm{C}_{2}$ and anti- $\mathrm{C}_{2}$-geometry, were located. For both compounds the lowest activation energy was reported for racemization via the anti-C $\mathrm{C}_{\mathrm{i}}$ pathway. ${ }^{31}$ These results are in general agreement with subsequent DFT studies of the uncatalyzed process. ${ }^{32,36,39}$ Figure 1 gives the molecular geometries as well as energies relative to the free compounds $\mathbf{1}$ and $\mathbf{2}$ obtained here at the PW6B95-D3(BJ)/Def2-TZVPP level of theory ${ }^{40-42}$ for all five possible transition structures for the chirality inversions of the binaphthyl systems of interest.
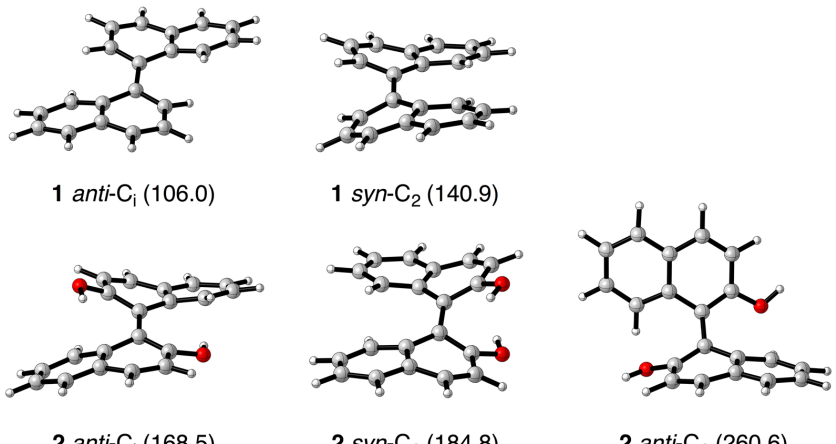

2 anti- $_{\mathrm{i}}(168.5)$

2 syn- $\mathrm{C}_{2}(184.8)$
Figure 1. Transition state geometries (optimized at the PBE$\mathrm{D} 3(\mathrm{BJ}) / 6-31 \mathrm{G}(\mathrm{d})$ level of theory) for the uncatalyzed racemizations of $\mathbf{1}$ and 2. Gibbs free activation energies at $298 \mathrm{~K}$ (PW6B95-D3(BJ)/Def2-TZVPP, $\mathrm{kJ} \mathrm{mol}^{-1}$ ) relative to free $\mathbf{1}$ and $\mathbf{2}$ are given in parenthesis.

In agreement with previous computational results, ${ }^{31,32,39}$ we find the racemization pathways via the anti-C $\mathrm{C}_{\mathrm{i}}$-type transition structures to be favorable and the resulting energy barriers of 106.0 (1) and 168.5 (2) $\mathrm{kJ} \mathrm{mol}^{-1}$ are in good agreement with the experimental results presented in Table 1.
Compared to the respective equilibrium structures, all transition structures feature distinctly distorted phenyl rings. The anti- $\mathrm{C}_{\mathrm{i}}$ and syn- $\mathrm{C}_{2}$-type transition structures assume nearplanar geometries with $\mathrm{C}^{2}-\mathrm{C}^{1}-\mathrm{C}^{1}-\mathrm{C}^{2}$ dihedral angles of $180.0^{\circ}$ $\left(\mathbf{1}\right.$, anti- $\left.\mathrm{C}_{\mathrm{i}}\right), 28.0^{\circ}\left(\mathbf{1}\right.$, syn- $\left.\mathrm{C}_{2}\right) 164.8^{\circ}\left(\mathbf{2}\right.$, anti- $\left.\mathrm{C}_{\mathrm{i}}\right)$ and $31.6^{\circ}(\mathbf{2}$, syn- $\mathrm{C}_{2}$ ). An exception is the anti- $\mathrm{C}_{2}$-type transition structure which assumes a tub-like geometry.

In order to examine the catalytic effect of adsorption onto graphene we optimized the complexes between all transition and equilibrium structures and a circumcircumcoronene flake. In each case, a systematic search of orientations of the substrates on the graphene flake was carried out to ensure that the lowest energy complex was located. Figure 2 displays topdown geometries for the catalyzed anti- $\mathrm{C}_{\mathrm{i}}$ and syn- $\mathrm{C}_{2}$-type transition structures located for BINOL (for top-down geometries of all equilibrium and transition structures see Figure S5 of the Supporting Information). Compared to the transition structures of the free racemizations no significant changes in the optimized geometries were observed with bond lengths in the transition structures of the catalyzed process all being within less than $0.01 \AA$ of those observed for the uncatalyzed process (for further details see Figures S1-4 of the Supporting Information). An exception forms the tub-shaped anti-C $\mathrm{C}_{2}$-type transition structure pertaining to the racemization of BINOL which for the catalyzed process converged to a near-planar anti-C $\mathrm{C}_{\mathrm{i}}$-geometry.
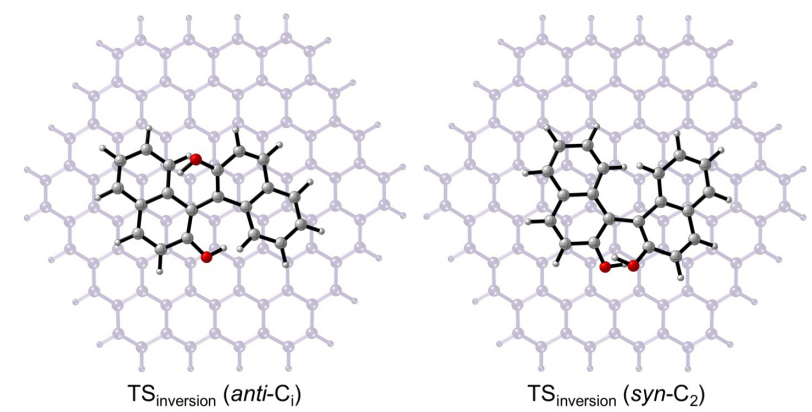
Figure 2. Transition state geometries (optimized at the PBE$\mathrm{D} 3(\mathrm{BJ}) / 6-31 \mathrm{G}(\mathrm{d})$ level of theory) for the catalyzed racemizations of 2 . Gibbs free activation energies are given in Table 2.

Figure 3 gives schematic potential energy surfaces (PESs) comparing the free and graphene-catalyzed chirality inversions via the anti-C-type transition structures of $\mathbf{1}$ and 2 . Table 2 summarizes the energy barriers and barrier reductions upon catalysis for both racemization pathways of $\mathbf{1}$ and $\mathbf{2}$.

Table 2 Reaction barrier heights for the uncatalyzed ( $\Delta G^{\ddagger}$ uncat) and catalyzed ( $\Delta G^{\dagger}$ cat) racemizations, stabilization

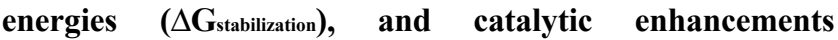
( $\Delta \Delta G_{\text {catalysis) }}^{\ddagger}$ (PW6B95-D3(BJ)/Def2-TZVPP, kJ $\mathrm{mol}^{-1}$ ) for both racemization pathways of 1 and 2 .

\begin{tabular}{|c|c|c|c|c|}
\hline Structure & $\Delta G^{\ddagger}$ uncat & $\Delta G_{\text {cat }}^{\dagger}$ & $\Delta \Delta \boldsymbol{G}^{\dagger}$ catalysis $^{a}$ & $\Delta \mathbf{G}_{\text {stabilization }}{ }^{b}$ \\
\hline 1 TS anti-C $C_{i}$ & 106.0 & 69.4 & 36.6 & 79.8 \\
\hline $1 \mathrm{TS} s y n-\mathrm{C}_{2}$ & 140.9 & 106.0 & 34.9 & 78.1 \\
\hline 2 TS anti-C $\mathrm{C}_{\mathrm{i}}$ & 168.5 & 120.4 & 48.1 & 79.1 \\
\hline 2 TS syn-C2 & 184.8 & 142.1 & 42.7 & 73.7 \\
\hline
\end{tabular}

${ }^{a} \Delta \Delta G^{\ddagger}$ catalysis $=\Delta G^{\ddagger}$ uncatalyzed $-\Delta G^{\ddagger}$ catalyzed. ${ }^{b}$ Estimated as the difference in Gibbs-free energy between the complexed transition structure (TS) and free nanoflake and TS.

Similar to molecular geometries, pathway preferences do not change upon catalysis and the racemizations via the anti- $\mathrm{C}_{\mathrm{i}-}$ type transition structures remain favorable, resulting energy barriers of 69.4 and $120.4 \mathrm{~kJ} \mathrm{~mol}^{-1}$ for the racemizations of 1 and 2, respectively. Compared to the uncatalyzed racemizations the presence of the graphene flake catalyst significantly reduces the activation energies of all catalyzed inversions. In particular, barrier reductions of 36.6 and $48.1 \mathrm{~kJ} \mathrm{~mol}^{-1}$ are observed for the racemizations of $\mathbf{1}$ and $\mathbf{2}$ via the favored anti-

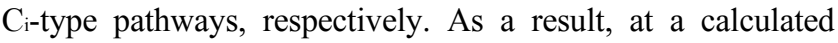
half-life of $163 \mathrm{~ms}$ the racemization of $\mathbf{1}$ is expected to occur readily at room temperature in the presence of graphene. ${ }^{43}$

Since the transition structures remain nearly identical when adsorbed onto the graphene flake, the observed reaction barrier reductions are not expected to be due to geometric changes reducing strain or steric interactions but rather the differential abilities of equilibrium and transition structures to form stabilizing interactions with the catalyst. In order to examine this further we calculate the single point energies of the transition and equilibrium structures of the catalyzed process with the catalyst removed. As expected from molecular geometries, we observe only a minimal increase in energy of $1.5 \mathrm{~kJ} \mathrm{~mol}^{-1}$ in the favored anti-C $\mathrm{C}_{\mathrm{i}}$ type transition structures for both $\mathbf{1}$ and $\mathbf{2}$ compared to the structures pertaining to the uncatalyzed process. $^{43}$ In contrast, comparably larger destabilizations of 6.8 (1) and 10.0 (2) $\mathrm{kJ} \mathrm{mol}^{-1}$ are observed for the equilibrium structures. Thus, disproportionate stabilizing interactions between substrate and graphene flake catalyst at the transition states compared to the reactants and, to a small extent, ground state destabilization can be identified as the driving forces of catalysis here.

As illustrated in Figure 3, the equilibrium structures of 1,1binaphthyl and BINOL are stabilized by 43.2 and $31.0 \mathrm{~kJ} \mathrm{~mol}^{-}$ ${ }^{1}$, respectively in the reactant complexes with the graphene flake compared to the free optimized biaryl and catalyst. The favorable anti- $\mathrm{C}_{i}$ type transition structures, on the other hand, are stabilized by 79.8 (1) and 79.1 (2) $\mathrm{kJ} \mathrm{mol}^{-1}$ in their complexes with the catalyst compared to the free inversion transition structures and catalyst (Table 2). The origin of these large differences in stabilization energies between equilibrium and transition structures lies in simple shape complementarity between the near-planar transition structures and the twodimensional catalyst which becomes apparent upon inspection of the adsorption complexes illustrated in Figure 3. In the reactant complexes unfavorable $C^{2}-C^{1}-C^{1}-C^{2}$ dihedral angles of $125.5^{\circ}(\mathbf{1})$ and $115.5^{\circ}(2)$ mean that only one naphthyl group can interact with the graphene nanoflake via $\pi-\pi$ interactions whereas the second naphthyl group is rotated such that only two $\mathrm{CH}-\pi$ interactions are possible. In the transition structures of the preferred anti-Ci-type $\mathrm{C}^{2}-\mathrm{C}^{1}-\mathrm{C}^{1}-\mathrm{C}^{2}$ dihedral angles of $177.4^{\circ}$ and $160.6^{\circ}$ for $\mathbf{1}$ and $\mathbf{2}$, respectively give the molecules near-planar geometries. This allows for both naphthyl groups to be stabilized by the graphene flake via $\pi-\pi$ interactions, partially compensating for the destabilizing strain energy associated with the distortion of the phenyl rings at the transition states.

In summary, while modified graphene has been used for catalytic applications and $\pi$-interactions are commonly exploited for selectivity enhancement in organocatalysts, both graphene and $\pi-\pi$ interactions generally play supporting roles in catalysis. Here, we provide an example of an organic transformation substantially accelerated by unmodified graphene in which extensive $\pi-\pi$ interactions act as the main driving force of catalysis. The observed catalytic effect results from application of the simple concept of shape complementarity: The catalyst geometry closely matches the transition state geometry allowing for extensive non-covalent interactions, whilst the reactant, being "ill-fitted" for interactions with the catalyst, is stabilized to a significantly lesser extent. This disproportionate stabilization of the transition structure over the reactant brings down the overall activation energy of the chemical process. In the case of the chirality inversions of binaphthyl compounds $\mathbf{1}$ and $\mathbf{2}$ here, the twisted reactant has to pass through a nearplanar transition structure in order to undergo racemization. Containing two aromatic naphthyl units, the near-planar transition structures of 1 and $\mathbf{2}$ are well suited for extensive $\pi$ - $\pi$ interactions with a 2D graphene flake. This affords barrier reductions of 36.6 (1) and 48.1 (2) $\mathrm{kJ} \mathrm{mol}^{-1}$.

Graphene, being purely carbon-based, is an attractive catalyst material for economic and sustainability considerations. We hope that the catalytic racemizations presented here will inspire further explorations into catalysis by unmodified nanocarbon materials and will find applications (e.g., in dynamic kinetic resolution) utilizing non-covalent $\pi-\pi$ interactions to accelerate chemical processes.

\section{COMUTATIONAL METHODS}

The geometries of all structures in this study were optimized at the PBE-D3(BJ)/6-31G(d) level of theory ${ }^{41,45}$ and equilibrium and transition structures were verified through vibrational frequency calculations at the same level of theory. Intrinsic reaction coordinates were calculated to confirm the connectivity of transition structures to the relevant equilibrium structures. In order to obtain more accurate energies single point energy calculations were carried out on the optimized structures using the PW6B95-D3(BJ) density functional in combination with the Def2-TZVPP basis set. ${ }^{40-42}$ All calculations were 
carried out using the Gaussian16 software package. ${ }^{46}$ 3D structural representations were generated using CYLview. ${ }^{47}$

\section{ASSOCIATED CONTENT}

\section{Supporting Information}

The Supporting Information is available free of charge on the ACS Publications website.

Cartesian coordinates of all optimized structures, structural representations providing all bond lengths and additional structural representations of the complexes between reactants and transition structures and catalyst. (PDF)

\section{AUTHOR INFORMATION}

\section{Corresponding Author}

*amir.karton@uwa.edu.au.

\section{Author Contributions}

Conceptualization: A.A.K. and A.K.; Methodology: A.A.K. and A.K.; Formal Analysis: A.A.K.; Investigation: A.A.K. and A.K.; Writing Original Draft: A.A.K.; Writing Review and Editing: A.A.K. and A.K.; Figure Preparation: A.A.K.; Supervision: A.K.; Project administration: A.K. All authors have given approval to the final version of the manuscript.

\section{Notes}

The authors declare no competing financial interest.

\section{ACKNOWLEDGMENT}

We acknowledge resources from the National Computational Infrastructure (NCI), supported by the Australian Government, and system administration support provided by the Faculty of Science at the University of Western Australia to the Linux cluster of the Karton group. We gratefully acknowledge the provision of a Forrest Research Foundation Scholarship and an Australian Government Research Training Program Stipend (to A.A.K.), and an Australian Research Council (ARC) Future Fellowship (to A.K.; Project No. FT170100373).

\section{REFERENCES}

1. Allen, M. J.; Tung, V. C.; Kaner, R. B., Honeycomb Carbon: A Review of Graphene. Chem. Rev. 2010, 110 (1), 132-145.

2. Liu, Y.; Dong, X.; Chen, P., Biological and chemical sensors based on graphene materials. Chem. Soc. Rev. 2012, 41 (6), 2283-2307.

3. Baptista, F. R.; Belhout, S. A.; Giordani, S.; Quinn, S. J., Recent developments in carbon nanomaterial sensors. Chem. Soc. Rev. 2015, 44 (13), 4433-4453.

4. Perreault, F.; Fonseca de Faria, A.; Elimelech, M., Environmental applications of graphene-based nanomaterials. Chem. Soc. Rev. 2015, 44 (16), 5861-5896.

5. Yang, T.; Zhao, X.; He, Y.; Zhu, H., 6 - Graphene-Based Sensors. In Graphene, Zhu, H.; Xu, Z.; Xie, D.; Fang, Y., Eds. Academic Press: 2018; pp 157-174.

6. Dai, L., Carbon-Based Metal-Free Catalysts, 2 Volumes: Design and Applications. Wiley: 2018.

7. Liu, X.; Dai, L., Carbon-based metal-free catalysts. Nat. Rev. Mater. 2016, 1, 16064.
8. Machado, B. F.; Serp, P., Graphene-based materials for catalysis. Catal. Sci. Technol. 2012, 2 (1), 54-75.

9. $\quad \mathrm{Su}, \mathrm{D} . \mathrm{S}$.; Perathoner, S.; Centi, G., Nanocarbons for the Development of Advanced Catalysts. Chem. Rev. 2013, 113 (8), 5782-5816.

10. Navalon, S.; Dhakshinamoorthy, A.; Alvaro, M.; Garcia, H., Carbocatalysis by Graphene-Based Materials. Chem. Rev. 2014, 114 (12), 6179-6212.

11. Hu, M.; Yao, Z.; Wang, X., Graphene-Based Nanomaterials for Catalysis. Ind. Eng. Chem. Res. 2017, 56 (13), 3477-3502.

12. Karton, A., Inversion and rotation processes involving nonplanar aromatic compounds catalyzed by extended polycyclic aromatic hydrocarbons. Chem. Phys. Lett. 2014, 614, 156-161.

13. Denis, P. A., Pristine Graphene-Based Catalysis: Significant Reduction of the Inversion Barriers of Adsorbed and Confined Corannulene, Sumanene, and Dibenzo[a,g]corannulene. $J$. Phys. Chem. A 2015, 119 (22), 5770-5777.

14. Krenske, E. H.; Houk, K. N., Aromatic Interactions as Control Elements in Stereoselective Organic Reactions. Acc. Chem. Res. 2013, 46 (4), 979-989.

15. Wheeler, S. E.; Seguin, T. J.; Guan, Y.; Doney, A. C., Noncovalent Interactions in Organocatalysis and the Prospect of Computational Catalyst Design. Acc. Chem. Res. 2016, 49 (5), 10611069.

16. Neel, A. J.; Hilton, M. J.; Sigman, M. S.; Toste, F. D., Exploiting non-covalent $\pi$ interactions for catalyst design. Nature 2017, 543, 637 .

17. Mattson, A. E., Tricks for noncovalent catalysis. Science 2017, 358 (6364), 720 .

18. Davis, H. J.; Phipps, R. J., Harnessing non-covalent interactions to exert control over regioselectivity and site-selectivity in catalytic reactions. Chem. Sci. 2017, 8 (2), 864-877.

19. Toste, F. D.; Sigman, M. S.; Miller, S. J., Pursuit of Noncovalent Interactions for Strategic Site-Selective Catalysis. Acc. Chem. Res. 2017, 50 (3), 609-615.

20. Brunel, J. M., BINOL: A Versatile Chiral Reagent. Chem. Rev. 2005, 105 (3), 857-898.

21. Brunel, J. M., Update 1 of: BINOL: A Versatile Chiral Reagent. Chem. Rev. 2007, 107 (9), PR1-PR45.

22. Parmar, D.; Sugiono, E.; Raja, S.; Rueping, M., Complete Field Guide to Asymmetric BINOL-Phosphate Derived Brønsted Acid and Metal Catalysis: History and Classification by Mode of Activation; Brønsted Acidity, Hydrogen Bonding, Ion Pairing, and Metal Phosphates. Chem. Rev. 2014, 114 (18), 9047-9153.

23. Cooke, A. S.; Harris, M. M., 437. Ground-state strain and other factors influencing optical stability in the 1,1 -binaphthyl series. J. Chem. Soc. (Resumed) 1963, (0), 2365-2373.

24. Colter, A. K.; Clemens, L. M., Solvent Effects in the Racemization of 1,1'-Binaphthyl. A Note on the Influence of Internal Pressure on Reaction Rates1. J. Phys. Chem. 1964, 68 (3), 651-654.

25. Cooke, A. S.; Harris, M. M., Optical activity in the 1,1 binaphthyl series. Energy barriers to racemisation of 8 -substituted 1,1 -binaphthyls. J. Chem. Soc. C: Org. 1967, (0), 988-992.

26. Gamba, A.; Rusconi, E.; Simonetta, M., A conformational study of phenyl- and naphthyl-naphthalenes. Tetrahedron 1970, 26 (3), 871-877.

27. Liljefors, T.; Carter, R. E., The configurational inversion of methyl-substituted 1,1 -binaphthyls as studied by molecular mechanics. Tetrahedron 1978, 34 (10), 1611-1615.

28. Leister, D.; Kao, J., Theoretical studies of rotational barriers in 1,1 -biisoquinoline, 2,2 -biquinoline and substituted styrenes, alkenyl-naphthalenes, and alkyl-binaphthyls. J. Mol. Struct.: THEOCHEM 1988, 168, 105-118.

29. Tsuzuki, S.; Tanabe, K.; Nagawa, Y.; Nakanishi, H., Calculations of internal rotational pathways of peri substituted naphthalenes by molecular mechanics. J. Mol. Struct. 1990, 216, 279295. 
30. Kranz, M.; Clark, T.; Schleyer, P. v. R., Rotational barriers of 1,1'-binaphthyls: a computational study. J. Org. Chem. 1993, 58 (12), 3317-3325.

31. Meca, L.; eha, D.; Havlas, Z., Racemization Barriers of 1,1'-Binaphthyl and 1,1'-Binaphthalene-2,2'-diol: A DFT Study. $J$. Org. Chem. 2003, 68 (14), 5677-5680.

32. Sahnoun, R.; Koseki, S.; Fujimura, Y. Theoretical investigation of 1,1'-bi-2-naphthol isomerization. J. Mol. Struct. 2005, 735-736, 315-324.

33. Nori-shargh D.; Asadzadeh S.; Ghanizadeh F.-R.; Deyhimi F.; Amini M. M.; Jameh-Bozorghi S., Ab initio study of the structures and dynamic stereochemistry of biaryls. J. Mol. Struct.: THEOCHEM 2005, 717, 41-51.

34. Da, L.-G.; Lu, T.-T.; Xiang, M.; He, T.-J.; Chen, D.-M. DFT study on the structure and racemization mechanism of 1,1'binaphthalene-8,8'-diol. Chin. J. Chem. Phys. 2008, 21, 367-375.

35. Abdellah, I.; Boggio-Pasqua, M.; Canac, Y.; Lepetit, C.; Duhayon, C.; Chauvin R. Towards the limit of atropochiral stability: HMIOP, an N-heterocyclic carbene precursor and cationic analogue of the H-MOP ligand. Chem.-Eur. J. 2011, 17, 5110-5115.

36. Sanz Garcia, J.; Lepetit, C.; Canac, Y.; Chauvin, R.; BoggioPasqua, M. Enantiomerization pathway and atropochiral stability of the BINAP ligand: A density functional theory study. Chem.-Asian J. 2014, 9, 462-465.

37. Patel, D. C.; Woods, R. M.; Breitbach, Z. S.; Berthod, A.; Armstrong, D. W., Thermal racemization of biaryl atropisomers. Tetrahedron: Asymmetry 2017, 28 (11), 1557-1561.

38. Da, L.-G.; He, J.; Hu, L.-F., DFT study on the structure and racemization mechanism of 2-amino-2 -hydroxy-1,1 -binaphthyl. $J$. Phys. Org. Chem. 2019, 32 (2), e3900.

39. Tkachenko, N. V.; Scheiner, S., Optical Stability of 1,1 Binaphthyl Derivatives. ACS Omega 2019, 4 (3), 6044-6049.

40. Zhao, Y.; Truhlar, D. G., Design of Density Functionals That Are Broadly Accurate for Thermochemistry, Thermochemical Kinetics, and Nonbonded Interactions. J. Phys. Chem. A 2005, 109 (25), 5656-5667.
41. Grimme, S.; Ehrlich, S.; Goerigk, L. Effect of the damping function in dispersion corrected density functional theory. $J$. Comput. Chem. 2011, 32, 1456-1465.

42. Weigend, F.; Ahlrichs, R., Balanced basis sets of split valence, triple zeta valence and quadruple zeta valence quality for $\mathrm{H}$ to Rn: Design and assessment of accuracy. Phys. Chem. Chem. Phys. 2005, 7 (18), 3297-3305.

43. The Eyring equation was used to calculate the rate constant and resulting half-life.

44. Only slightly larger changes of 2.7 (1) and 4.5 (2) $\mathrm{kJ} \mathrm{mol}^{-1}$ are observed for the transition structures of syn-C2 type geometry.

45. Perdew, J. P.; Burke, K.; Ernzerhof, M., Generalized Gradient Approximation Made Simple. Phys. Rev. Lett. 1996, 77 (18), 3865-3868.

46. M. J. Frisch, G. W. Trucks, H. B. Schlegel, G. E. Scuseria, M. A. Robb, J. R. Cheeseman, G. Scalmani, V. Barone, G. A. Petersson, H. Nakatsuji, X. Li, M. Caricato, A. V. Marenich, J. Bloino, B. G. Janesko, R. Gomperts, B. Mennucci, H. P. Hratchian, J. V. Ortiz, A. F. Izmaylov, J. L. Sonnenberg, D. Williams-Young, F. Ding, F. Lipparini, F. Egidi, J. Goings, B. Peng, A. Petrone, T. Henderson, D. Ranasinghe, V. G. Zakrzewski, J. Gao, N. Rega, G. Zheng, W. Liang, M. Hada, M. Ehara, K. Toyota, R. Fukuda, J. Hasegawa, M. Ishida, T. Nakajima, Y. Honda, O. Kitao, H. Nakai, T. Vreven, K. Throssell, J. A. Montgomery, Jr.., J. E. Peralta, F. Ogliaro, M. J. Bearpark, J. J. Heyd, E. N. Brothers, K. N. Kudin, V. N. Staroverov, T. A. Keith, R. Kobayashi, J. Normand, K. Raghavachari, A. P. Rendell, J. C. Burant, S. S. Iyengar, J. Tomasi, M. Cossi, J. M. Millam, M. Klene, C. Adamo, R. Cammi, J. W. Ochterski, R. L. Martin, K. Morokuma, O. Farkas, J. B. Foresman, D. J. Fox, Gaussian 16, Revision A.03, Gaussian, Inc., Wallingford, CT, 2016.

47. CYLview, 1.0b; Legault, C. Y., Université de Sherbrooke, 2009 (http://www.cylview.org). 
Insert Table of Contents artwork here

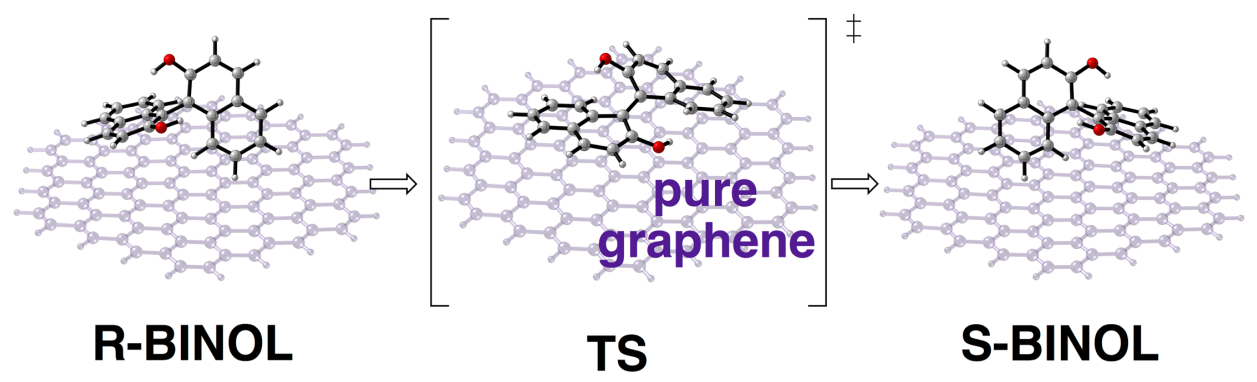

